\title{
UNA MIRADA A LA TRAYECTORIA LEXICOLÓGICA Y LEXICOGRÁFICA DE MANUEL ALVAR EZQUERRA
}

\author{
María Auxiliadora Castillo Carballo \\ Universidad de Sevilla
}

\section{Resumen}

El presente artículo se centra en realizar un recorrido por la trayectoria investigadora del profesor Manuel Alvar Ezquerra. Su dedicación al trabajo, enfocado hacia la lexicología y la lexicografía, ha dado lugar a una extensa obra en las que ha abordado siempre con rigor cuanto se proponía. Los repertorios de diversa índole que ha elaborado son, sin duda alguna, referentes en la producción lexicográfica, por lo que ha sido y sigue siendo imprescindible para el quehacer futuro.

Palabras clave: Lexicología, lexicografía, diccionario, Manuel Alvar Ezquerra.

\section{A LOOK AT THE LEXICOLOGICAL AND LEXICOGRAPHIC CAREER OF MANUEL ALVAR EZQUERRA}

\begin{abstract}
This article focuses on a journey through the research career of Professor Manuel Alvar Ezquerra. His dedication to work, focused on lexicology and lexicography, has led to an extensive work in which he has always addressed with rigor his goals. The repertoires of diverse nature that he has elaborated are, undoubtedly, referents in the lexicographical production, for what he has been and continues to be essential for future research.

Keywords: Lexicology, Lexicography, dictionary, Manuel Alvar Ezquerra.
\end{abstract}


Aunque las primeras manifestaciones sobre práctica lexicográfica son muy anteriores a la consolidación de la vertiente teórica, lo cierto es que en la actualidad no hay discusión en que una no se sustancia sin la otra. Un claro ejemplo de esta necesaria relación es Manuel Alvar Ezquerra, al que voy a dirigir la mirada en estas páginas, pues desde sus inicios en el mundo de la filología manifestó un sólido interés por los dos aspectos; de ahí su legado metalexicográfico y los repertorios de diversa índole que ha confeccionado. No cabe duda de que su magisterio en la universidad, en la que se ha ocupado de la lexicología y la lexicografía del español, se ha reflejado en su producción investigadora.

Resulta complejo hacer un balance detallado y completo de todas las obras que se pueden ubicar en algunas de las facetas referidas anteriormente, por ello voy a aludir a aquellas (no necesariamente de forma cronológica) que, de alguna manera, son imprescindibles en una vida entregada a las voces que configuran la lengua.

Una de sus primeras publicaciones fue el Proyecto de lexicografía española (1976), que supuso una aproximación rigurosa no solo a la elaboración de un tesoro de la lengua, pues se explican con detenimiento todas las dificultades que se traducen del trabajo que conlleva una tarea de gran envergadura, sino también al conocimiento detallado de los entresijos que conlleva la confección de un diccionario del español actual, de tal manera que se hace hincapié en la necesidad de fijar la atención en «realizaciones concretas de la lengua y no en unas apreciaciones formuladas a priori» (Alvar Ezquerra, 1976: 156), lo que implica manejar un material suficientemente extenso, que atienda tanto a la lengua coloquial y literaria como también al lenguaje científico y técnico. Asimismo, no cabe desdeñar su predisposición desde el principio a aunar la informática con la lexicografía, pues el último capítulo de este libro lo dedicó precisamente a la asistencia de los ordenadores en la elaboración de las obras lexicográficas. En ese sentido, ya señalaba que los tipos de obras propuestas en las páginas precedentes no se podían «concebir hoy sin la ayuda de un instrumental perfeccionado, como son los ordenadores electrónicos» (Alvar Ezquerra, 1976: 205). Son estas afirmaciones y muchas otras que se exponen en este trabajo las que contribuirán a moldear las teorías metalexicográficas que fueron apareciendo en las décadas siguientes, pero que, sin duda, ya perfilaban el buen hacer de un lexicógrafo imprescindible.

$\mathrm{Su}$ constante simbiosis con la teoría y la práctica lo llevó a acercarse en una guía bibliográfica, bajo el título Lexicología y Lexicografía (Alvar Ezquerra, 1983), a un número relevante de estudios y a una serie de diccionarios de trascendencia hasta el momento. Su contribución no se ciñó a una mera reseña de cada una de estas publicaciones, sino que hábilmente, más allá de dar cuenta de su contenido y del análisis del experto, focalizó la atención 
en determinados aspectos que abrían nuevas vías de acercamiento a la investigación, con una evidente función orientadora ${ }^{1}$. Y así es, pues, pese a que en la Introducción el propio autor decía únicamente que «la intención perseguida es la de poner un instrumento de trabajo en manos de los estudiantes universitarios y del profesorado de enseñanza media y superior» (Alvar Ezquerra, 1983: 7), más adelante sí reconocía, al puntualizar que la guía podía haber sido más extensa, que su propósito era «ofrecer los primeros elementos para iniciarse en la lexicología y en la lexicografía, y otros pocos más para mostrarle las tendencias y posibilidades de investigación que ofrecen nuestros especialistas» (Alvar Ezquerra, 1983: 8). Aparecen, por tanto, reseñadas contribuciones de calado para la metalexicografía posterior, en especial de autores franceses de relevancia, desde Matoré, Alan Rey o Rey-Debove a Guiraud, Jean y Claude Dubois o Bernard Quemada. No en vano, como Manuel Alvar señaló en una entrevista que le hicieron hace pocos años y publicada en el número 59 de la revista Cálamo FASPE, se marchó a Francia una vez terminados sus estudios universitarios con el fin de ampliar lo que había aprendido y se impregnó, bajo el magisterio de Quemada, del nacimiento de la moderna lexicografía y de la lingüística computacional (Sánchez Lobato, 2012: 4). Pero en la obra de la que vengo hablando también se encuentran los acertados comentarios de trabajos de gran interés pertenecientes al ámbito hispánico como «El diccionario que deseamos» de Menéndez Pidal (1945), Introducción a la lexicografía moderna de Julio Casares (1950) o Elementos de lexicografía. El Diccionario de construcción y régimen de R.J. Cuervo de Porto Dapena (1980). En definitiva, esta guía le sirvió para dar a conocer, por su formación, a autores de poca difusión en ese entonces, así como sus planteamientos teóricos, y para ocuparse de algunos repertorios de especial importancia hasta el momento, como el Diccionario general e ilustrado de la lengua española de Gili Gaya (1976 [1945], 3. a edición y 1. reimpresión), el Diccionario de uso del español de María Moliner (1966) o, por ejemplo, el Diccionario ideológico de la lengua española de Julio Casares (1959), del que hizo un pormenorizado análisis que obviamente no presagiaba que algo más de diez años después, en 1995, dirigiese su propio Diccionario ideológico de la lengua española, publicado por la editorial Biblograf (Alvar Ezquerra, 1995a), sin lugar a dudas, partiendo desde premisas más objetivas y de materiales propios, además de estar pensado para su utilización en la enseñanza media, aunque resulta lamentable que haya dejado de comercializarse. No obstante, antes de este diccionario, ya hubo otros de especial envergadura, por lo que cabe afirmar que desde muy pronto la producción lexicográfica fue uno de sus objetivos primordiales.

1 Resulta de interés el trabajo de Navarro Carrasco (1991), en el que de manera pormenorizada se desentraña esta obra. 
Si bien es cierto que publicó en 1983 junto con Aurora Miró un Diccionario de siglas y abreviaturas que le hizo conocer las dificultades que entrañaba la elaboración de cualquier repertorio, lo que le sirvió para la tarea que se le encomendó, en la misma fecha, de planificar y confeccionar la parte española de los diccionarios Duden por imágenes (Alvar Ezquerra, 1995b), el gran reto lexicográfico vino con la asunción de la responsabilidad de poner en marcha «la automatización, revisión, aumento y actualización del conocido Diccionario general ilustrado de la lengua española, el Vox» (Sánchez Lobato, 2012: 5), que vio la luz en 1987², lo que supuso que la editorial Anaya, antes Biblograf, creara un centro lexicográfico en Málaga, bajo su dirección, con la finalidad de actualizar los diccionarios Vox. De este modo, vinieron a engrosar la lista de repertorios, a los que tanto él como su equipo dedicaron con rigor su tiempo, obras como el Práctico-Vox. Diccionario ilustrado de la lengua española, el Diccionario manual ilustrado de la lengua española y el Diccionario actual de la lengua española, todos ellos publicados en 1990 (Alvar Ezquerra, 1990a, 1990b y 1990c, respectivamente). En la misma década, también estuvo a cargo del Diccionario para la enseñanza de la lengua española (Alvar Ezquerra, 1995c), del Diccionario general de la lengua española, Vox y del Diccionario esencial de la lengua española, Vox, los dos últimos de $1997^{3}$.

Su contribución a la lexicografía práctica en los años siguientes estaría especialmente ligada al ámbito universitario a través del desarrollo de varios proyectos de investigación, no sin las trabas e intermitencias propias de la Administración, y que darían importantes frutos. Se trata de repertorios de gran valor para el ámbito científico que poseen un denominador común, el de aunar obras lexicográficas distintas en un volumen. Esta idea insistente de que los investigadores tuviesen en una sola obra diversas aportaciones lexicográficas se materializó, por ejemplo, en el Tesoro léxico de las hablas andaluzas (2000). Ya en el título se anticipaba qué tipo de compilación se ponía a nuestra disposición. Un diccionario de diccionarios ${ }^{4}$. Esto supuso manejar un ingente número de datos, extraídos todos de importantes recopilaciones, como el Vocabulario andaluz de Alcalá Venceslada o el de Toro y Gisbert; o bien de catálogos de diversa índole, es decir, de restricción local, comarcal o provincial, o incluso mucho más específicos aún, que atendían, por ejemplo, por referir algunos, al léxico de las salinas de Huelva o al léxico

2 Resulta muy esclarecedor el análisis de Cerdá (1989) sobre este diccionario.

3 Véase Alvar Ezquerra (1997a y 1997b, respectivamente). Sobre el proceso de automatización y elaboración de una base de datos para la confección de los diccionarios Vox, véase Alvar Ezquerra, Blanco Rodríguez, López Guzmán y Pérez Lagos (1992: 427-435).

4 Se cimienta en ciento cuarenta y seis fuentes, lo que ha dado lugar a que posea unas cuarenta mil entradas que vienen a sumar más de ochenta y seis mil acepciones. Véase la reseña que hizo de esta obra Navarro Carrasco (2001). 
del olivo y la almazara de Jaén. Pero no solo esto sirvió para su elaboración. $\mathrm{Su}$ empresa era mucho más ambiciosa. También se propuso incorporar el vocabulario que se recogía en el Atlas lingüistico y etnográfico de Andalucía. Para ello se sirvió de la documentación que ya existía y que se encontraba ordenada en fichas, en las que se registraban todas las palabras del Atlas, si bien con la desestimación de las variantes fonéticas (proceder que imperó, obviamente, en la sistematización de toda la nómina macroestructural que lo compondría). Esto, sin lugar a dudas, allanó el camino, pero no se escapó de la observación y revisión minuciosa. Igualmente, tuvo a bien incorporar aquellos vocablos y sentidos que en el diccionario académico de ese entonces, la edición de 1992, recogía anotados con la marcación And. (Andalucía), e hizo lo mismo con el Diccionario general ilustrado de la lengua española, Vox, ya referido, el de 1987. Y como todo lo que se concibe con un sentido total, homogeneizado y bien cimentado, no podía dejar fuera de análisis para su inclusión en este macroproyecto de diccionario de diccionarios las voces que aparecían listadas en monografías, tesinas y tesis doctorales, como él mismo ha señalado, con el previo permiso de sus autores, y, en ocasiones, a falta de recuentos finales procedió a extraerlos de su contenido ${ }^{5}$. A pesar de todos los desvelos para lograr acopiar un ingente caudal de voces propias de las hablas andaluzas, la determinación del investigador insaciable y en constante necesidad de mejorar el trabajo ya hecho le hacía tener la convicción de que no era la publicación del Tesoro

[...] el punto de llegada de un largo recorrido realizado con el esfuerzo de todos, sino el de partida [...]. Ahora nos queda contemplar la labor realizada, ver cuáles son sus carencias y recoger lo que todavía anda desperdigado y en la boca de nuestros hablantes (Alvar Ezquerra, 2000: 18).

Al margen de que estos deseos pudieran ser factibles, esta obra sí que ha servido para ahondar en el análisis y estudio del vocabulario andaluz, pues a partir de todo el contenido que en ella se encierra, tanto del lemario como de la información microestructural que se recoge, se han realizado tesis doctorales y se han publicado diversos artículos científicos sobre aspectos léxicos concretos ${ }^{6}$.

La idea de compilación y acopio ya había comenzado con el Vocabulario de indigenismos en las crónicas de Indias (Alvar Ezquerra, 1997c), pues, no en vano, también se nutrió de diferentes fuentes entre las que se encontraban las literarias de las crónicas que facilitaron los contextos de las voces que se

\footnotetext{
5 Para todos los entresijos que rodeó la confección de este repertorio, véase fundamentalmente Alvar Ezquerra (1996a y 2004).

6 Algunos ejemplos son los trabajos de Castillo Carballo y García Platero (2001), Castillo Carballo (2004 y 2013), García Platero (2004), etc.
} 
registraron y, por supuesto, las que partían de algunas publicaciones, pero también de índices, glosarios y de un número considerable de memorias de licenciaturas y tesis doctorales de variada procedencia y realizadas en un amplio periodo de tiempo. Todo ello se completó, a falta de algunos materiales y como explica el propio autor en el Prólogo (Alvar Ezquerra, 1997c: X), con la «lectura y espigueo de los términos». En la tarea de confección de este repertorio también tuvo que adoptar unos criterios claros que desecharan lo que en los datos extraídos no fuera un indigenismo, aunque se refiriera a realidades americanas o especialmente conocidas por provenir de América; como tampoco se estimaron, obviamente, los castellanismos que se acomodaron en las lenguas indígenas. En la labor de depuración de los materiales recabados también se tuvo en cuenta la unificación de las variantes fonéticas o gráficas de los vocablos, y en ese sentido se optó por la fiabilidad de la fuente y por la mayor adecuación a la ortografía imperante. El resultado fue una obra bien hecha, que, de nuevo, ponía a disposición del usuario curioso e interesado datos que estaban dispersos.

Fruto de un proyecto de investigación que se desarrolló durante muchos años de trabajo, vio la luz el Nuevo tesoro lexicográfico del español (s. XIV-1726) realizado junto con Lidio Nieto Jiménez y publicado en 2007. La idea de ambos autores fue la de continuar la labor truncada del Tesoro lexicográfico de Samuel Gili Gaya, aunque desde unos nuevos planteamientos, lo que hizo que ambos se diferenciaran de manera sustancial. El punto de partida fue confeccionar una obra que rastreara la historia de un elevadísimo número de entradas, por lo que se consideró pertinente retroceder en el tiempo, tomando como referencia todos los repertorios léxicos anteriores a 1500 en los que apareciese el español, con lo cual se superó la fecha de inicio de datación a la que atendió Gili Gaya, establecida en 1492. La razón de este proceder la explicaron los propios autores:

Hemos ampliado notablemente la fecha de inicio, tanto por los deseos expresados en su día por algunos de los reseñadores del Tesoro lexicográfico (1492-1726) de Gili Gaya, como por nuestras convicciones científicas e indagación de fuentes (Alvar Ezquerra y Nieto Jiménez, 2006: 365).

Asimismo, el número de obras que se tuvieron en cuenta también fue mayor, pues en el Tesoro de Gili Gaya se manejaron setenta y tres referencias y en la compilación de Alvar Ezquerra y Nieto Jiménez se registraron un total de ciento cuarenta y cinco, entre ellas diccionarios, glosarios y textos

7 Véanse detalles sobre esta ardua labor en Alvar Ezquerra (2012). No obstante, no son pocos los trabajos en los que fue explicando y analizando los pormenores del proceso de elaboración antes y después de su publicación. 
de índole científica y de léxico especializado. Todo en su conjunto dio lugar a una publicación de once volúmenes, con más de diez mil quinientas páginas que pusieron al servicio de los estudiosos la evolución, etimología y, en definitiva, la historia de gran parte de la nómina léxica del español.

En la misma línea de los tres últimos repertorios a los que me acabo de referir se encuentra el Diccionario de madrileñismos (Alvar Ezquerra, 2011), del que hubo dos ediciones en el mismo año. Se trata de una compilación de naturaleza contrastiva, pues se incluyeron solo aquellos vocablos que no tenían un uso general o que podían tener un empleo propio de la Comunidad de Madrid o con un sentido algo distinto. Las fuentes de las que se partió para su elaboración fueron muy diversas, no necesariamente lexicográficas en su totalidad, aunque sí se acudió a vocabularios y glosarios, pero también formaron parte del rastreo revistas y libros de distinta naturaleza, obras misceláneas, monografías, incluso folletos turísticos o programas de fiestas locales. Tampoco faltaron fuentes orales y escritas provenientes de los medios de comunicación, como algunos suplementos regionales de periódicos, o bien noticias locales de radio o televisión. A pesar de todo, cabe destacar que se emplearon como método de recogida léxica, ante la evidencia de la escasez de voces pertenecientes a ámbitos de la actividad cotidiana y de la falta de suficiente documentación de algunas zonas, encuestas realizadas por diferentes localidades de la Comunidad a partir de un cuestionario que tomaba como modelo el que sirvió de base a Manuel Alvar en la elaboración del Atlas lingüistico y Etnográfico de España y Portugal o de los de Andalucía, Aragón, Navarra y la Rioja. En este diccionario se recogieron, por tanto, voces castizas, del ámbito rural y urbano, antiguas, técnicas, populares, de labores y costumbres tradicionales, así como palabras de argot o aquellas que designan platos típicos de la región. Toda esta diversidad no impidió que en la obra imperase una perfecta planificación en el diseño de cada artículo lexicográfico, con el uso del contorno, la información gramatical, la fuente de procedencia, las localidades en las que se había corroborado la presencia de la voz en cuestión, así como con la reproducción de la definición del DRAE, cuando se daba proximidad en las acepciones, y la presencia de la medioestructura para indicar las piezas léxicas relacionadas y sus variantes ${ }^{8}$. Una vez más, el autor consiguió dejarnos para el futuro un ejemplo de repertorio regional, exponente del buen quehacer lexicográfico.

Otro de los desvelos de Manuel Alvar Ezquerra ha sido analizar las tendencias léxicas del momento. Ya he hecho referencia más arriba al Diccionario

8 Sobre esta obra resultan de interés una reseña de García Aranda (2012) y también de Cazorla Vivas y Aranda García (2012), que ilustra y se refiere a otras obras ya abordadas en este trabajo. 
de siglas, por lo que conviene darle un lugar especial a una de sus producciones lexicográficas de mayor relevancia en este ámbito: el Diccionario de voces de uso actual, cuya primera edición se publicó en 19949. El nombre estaba justificado porque, como se señaló en el Prólogo, las entradas que contenía el repertorio no eran necesariamente neologismos, por mucho que inicialmente pueda estar claro el concepto: «aquella voz que no ha sido empleada antes en la lengua» (Alvar Ezquerra, 1994: v), lo que rápidamente se desmonta en cuanto se procede a comprobar si esto es así, pues no se cuenta con un registro de primeras documentaciones, ni, por ejemplo, como el propio autor nos dice, con «un organismo en el que vayan quedando censadas las palabras necesarias para nombrar las nuevas realidades» (Alvar Ezquerra, 1994: v). Estas razones y otras de peso justificaron que se tomara como referencia el diccionario académico vigente, el de 1992, de tal manera que la nómina de entradas estuvo formada por las voces no incluidas en el repertorio oficial; decisión arbitraria, como se reconoce, pero de indudable objetividad y operatividad. Asimismo, las fuentes documentales que se emplearon para la confección del corpus léxico y para las citas que en la información microestructural lo acreditaban, procedían en su totalidad de la prensa periódica, tanto de tirada nacional como regional o local, así como de semanarios de información general y revistas mensuales de divulgación científica. La utilidad de esta obra es indiscutible, pues aunque no sea exactamente un diccionario de neologismos, sí contiene muchas voces de nueva factura. En ese sentido, una de las finalidades del repertorio, como ya se apuntaba en las páginas preliminares, era la de «ayudar a fijar el comienzo del uso de una palabra en la lengua» (Alvar Ezquerra, 1994: viII), pero también la de servir de testimonio de un momento concreto, como si se tratase de un álbum de palabras dispuesto para rememorar el pasado ${ }^{10}$. Con esta edición no acabó todo, pues años más tarde, en 2003, vio la luz otra bastante ampliada, ahora bajo el nombre Nuevo diccionario de voces de uso actual, que venía a continuar la labor de recopilación de los usos léxicos que se iban incorporando a la lengua. De cinco mil trescientas nueve entradas se pasó a doce mil trescientas ochenta y nueve; de cinco mil seiscientas diez acepciones, a trece mil quinientas sesenta y tres; y de ocho mil seiscientas sesenta y nueve citas, a veintitrés mil seiscientas cuatro. Las cifras hablan solas. El incremento fue más que considerable, aunque esta vez la edición académica de contraste fue la del DRAE de 2001 y las fuentes documentales se actualizaron teniendo en cuenta además, en ocasiones, la prensa americana, consultada a través de Internet.

\footnotetext{
9 La realización de este diccionario también fue fruto de un proyecto de investigación financiado.

10 Conviene tener presente que no todas las voces nuevas que aparecen tienen vida eterna; algunas de ellas son demasiado efímeras.
} 
En cualquier caso, tanto una edición como la otra son un potencial para el estudio de los patrones de comportamiento en la creación y aparición de las unidades léxicas. No en vano, y como se refiere en nota en el Prólogo de esta edición (Alvar Ezquerra, 2004: viI), son muchos los trabajos que se han realizado (incluidos los del propio autor ${ }^{11}$ ) tomando como fuente los datos contenidos en el primero o segundo de los diccionarios, lo que pone de manifiesto los beneficios de este catálogo para los especialistas que indagan en el léxico. Pero también para los propios lexicógrafos y recopiladores de nuevas voces ha tenido trascendencia, pues, por ejemplo, muchas de las palabras y expresiones que se registraban en la primera edición se incorporaron en alguna medida en el DRAE de 2001². Del mismo modo, Manuel Seco y sus colaboradores lo tuvieron en cuenta para la elaboración del Diccionario del español actual, que ha tenido hasta la presente dos ediciones, la de 1999 y la de 2011. Y también cabe dejar constancia de que forma parte de las fuentes de referencia que se emplean en la publicación de neologismos a través del blog Martes neológico, iniciativa de divulgación lingüística del «Observatori de la Neologia», del grupo IUlaterm de la Universitat Pompeu Fabra y el Instituto Cervantes. El éxito de este diccionario parece, por tanto, indiscutible.

Con planteamientos teóricos, pero sin perder de vista la visión didáctica ${ }^{13}$, publicó su libro La formación de palabras en español, en el año 1993, aunque ha tenido numerosas ediciones. Pertenece a la colección Cuadernos de la Lengua Española de la editorial Arco Libros, por lo que el deseo de llegar a un público en etapas de formación estaba presente. De hecho, se ha utilizado y se utiliza en la docencia universitaria como material recomendado a los estudiantes. Como el propio autor señala, y con la lectura se puede comprobar, el enfoque no solo es normativo, sino también descriptivo. En esta obra se abordan los diferentes procedimientos de formación de palabras para los que utiliza, como señala en la Presentación (Alvar Ezquerra, 1993a: 7), ejemplos extraídos del corpus de neologismos que daría lugar al repertorio antes mencionado.

Manuel Alvar también ha defendido siempre que el diccionario es una herramienta fundamental para el aprendizaje de las lenguas. Como ya se ha señalado, se encargó de la dirección de catálogos lexicográficos en esta

11 Por citar algunos, véase Alvar Ezquerra (1998, 1999a, 1999b, 2006 o 2007), entre otros.

12 Al final de la segunda edición del Diccionario de voces de uso actual (Alvar Ezquerra, 2003) se recoge un apéndice con la relación completa de las piezas léxicas que se han eliminado debido al refrendo académico.

13 Esta vertiente, que siempre lo ha acompañado, lo llevó a publicar también un Manual de ortografía de la lengua española (Alvar Ezquerra y Medina Guerra, 1995) y un Manual de redacción y estilo (Alvar Ezquerra, Castillo Carballo, García Platero, Jiménez Cuenca y Medina Guerra, 1999). 
dirección. En el ámbito teórico también ha elaborado varios artículos que profundizan en la función glosodidáctica del diccionario ${ }^{14}$. Pero cabría reseñar su libro La enseñanza del léxico y el uso del diccionario, publicado en 2003, en el que abordó diferentes aspectos sobre la enseñanza de vocabulario, como la ortografía, la pronunciación o cuestiones de índole gramatical. Asimismo, se adentró en los problemas que acarrea la homonimia o los falsos amigos y no obvió la operatividad que supone para una óptima competencia léxica el control sobre las relaciones de contenido, la sinonimia y la antonimia. Tampoco desdeñó acercarse a los diferentes fenómenos fraseológicos, cuyo dominio conecta al aprendiz de una segunda lengua con la idiosincrasia del sistema. No terminó este libro sin atender, por un lado, a la frecuencia de las palabras, que ha de tener especialmente en cuenta el docente para no incurrir en una enseñanza y esfuerzo de aprendizaje baldíos y, por otro, sin orientar sobre qué debe contener un diccionario para que pueda resultar de utilidad al estudiante extranjero.

Todo lo dicho hasta ahora deja traslucir claramente que su producción científica es inagotable, tanto en lo que concierne a los aspectos diacrónicos como sincrónicos. Son muchos los artículos de revistas, capítulos de libros y ponencias en congresos nacionales e internacionales que ha publicado. Por ello, ha tenido a bien compilar un número considerable y representativo en algunas obras como la Lexicografía descriptiva (Alvar Ezquerra, 1993b), en la que se recogían los trabajos de casi diez años, comprendidos entre 1980 y 1990, que se adentraban en numerosas cuestiones metalexicográficas, por lo que se puede considerar un compendio imprescindible.

Mucho más reciente, de 2018, es la colección de artículos publicada en la sección Doble pleca. Investigaciones léxicas de la Colección Lingüística de la Universidad de Jaén, bajo el nombre Estudio en torno a las hablas andaluzas y otras cuestiones (Alvar Ezquerra, 2018), en la que se atiende a diferentes aspectos sobre las peculiaridades léxicas del área geográfica de análisis, así como al vocabulario general o restringido de algunas localidades, aunque se abre con un trabajo de naturaleza más global, sobre lexicografía dialectal, que fundamentalmente se centra en el tratamiento de las voces regionales en los diccionarios.

Desde una perspectiva diacrónica, otro de sus libros dedicado a recopilar trabajos publicados con anterioridad fue De antiguos y nuevos diccionarios

\footnotetext{
14 Véanse, entre otros, dos trabajos distantes en el tiempo; uno de ellos es una ponencia presentada en el IV Simposio Internacional de la Sociedad Española de Didáctica de la Lengua y la Literatura (Alvar Ezquerra, 1996b) y otro es un proyecto de innovación docente, que se encuentra en abierto en el repositorio de producción académica en la UCM (García Aranda, Alvar Ezquerra, Nuño Álvarez y Cazorla Vivas, 2016).
} 
del español (Alvar Ezquerra, 2002). Por la visión histórica de la lexicografía siempre ha tenido especial querencia y nunca ha dejado de dedicarle su tiempo, y lo sigue haciendo sin pausa. De hecho, sus pretensiones como experto siempre han ido más allá del estudio aislado del conjunto, pues así lo expuso en el Prólogo (Alvar Ezquerra, 2002: 10):

Desde hace muchos años vengo dedicando una buena parte de mi quehacer a elaborar una historia de los diccionarios del español que no sé cuándo podré terminar; pues la labor no es poca dada la diversidad de obras, y, sobre todo, porque no disponemos de un buen catálogo, tanto de obras y ediciones como de lugares donde se conservan ${ }^{15}$.

Algunos de los autores que analizó en este libro fueron Nebrija, Andrés Gutiérrez Cerezo, Richard Percyvall, Lorenzo Franciosini, Alejandro de Luna, Lorenzo Robles, Terreros, pero también se acercó a los diccionarios ideológicos del español o a los monolingües del s. xx, entre otros aspectos.

Al margen de las compilaciones de artículos, pero en la misma línea de la lexicografía histórica, Manuel Alvar Ezquerra publicó una obra de especial relevancia. Se trata de Las Nomenclaturas del español. Siglos XV-XIX (Alvar Ezquerra, 2013), donde se observa la labor minuciosa del investigador, no solo por la descripción de cada una de los repertorios, nomenclaturas, que analizó, sino por el acopio ingente de títulos, de marcado carácter didáctico, en el que las voces se clasifican tomando como punto de partida la idea de la realidad nombrada para desembocar en la palabra. Como señala el propio autor, aunque estos catálogos se alejen de los grandes diccionarios, conviene tenerlos en cuenta como una parte de la historia, pues como señala:

[...] son nombres bien conocidos los que figuran como autores de las nomenclaturas, y en todas las épocas: Nebrija, Oudin, Jerónimo de Tejada, Ambrosio de Salazar, Lorenzo Franciosini, el P. Esteban de Terreros, Francisco Sobrino, John Stevens, Núñez de Taboada y tantos otros (Alvar Ezquerra, 2013: 14).

En definitiva, se trata de un extraordinario trabajo que recorre un amplio periodo y que, aunque, en más de alguna ocasión, se disculpara Manuel Alvar porque alguna nomenclatura se le hubiese podido quedar fuera, es un legado de gran valor para esa parte de la historia de la lexicografía que aún tiene como deber, y que además, en su afán de recopilar y recopilar, supuso el germen de la Biblioteca Virtual de la Filología Española $(B V F E)^{16}$, pues la idea inicial era la de hacer una base de datos que recogiera todas las que

15 Precisamente, esas carencias que denunciaba en ese momento y que, obviamente, le preocupaban, poco después empezó a atajarlas gracias a un ambicioso proyecto, al que me referiré seguidamente, la Biblioteca Virtual de la Filología Española (BVFE).

16 En línea: <https://www.bvfe.es>. 
iba encontrando y que aún no había descrito. Pero obviamente se necesitaba de una mayor infraestructura para soportar tanto material que se iba añadiendo, pues no se podían desdeñar diccionarios de todo tipo, ni, como se pensó más tarde, gramáticas y tratados ortográficos, y recientemente diálogos, coloquios, frases, conversaciones, etc. Y esa necesidad de una infraestructura potente se tradujo en una plataforma, la $B V F E$, que bien diseñada podía garantizar el acceso a un número muy elevado de obras digitalizadas ya en la red y que se encontraban dispersas en lugares muy diversos. Desde 2010 estaba disponible, si bien como un recurso de la biblioteca de la Universidad Complutense de Madrid, pero a partir de 2014 ya se concibió como una entidad autónoma, y un año más tarde se comenzaron a añadir sucintas fichas biobibliográficas para cada uno de los autores contenidos en la BVFE, en la que se daba cuenta de su biografía, algunos comentarios sobre su obra, una relación de sus publicaciones en relación con la lengua española y una bibliografía específica ${ }^{17}$. Esta herramienta digital nos lleva de nuevo a la idea, referida más arriba, de poner al servicio de los investigadores un material que conjugue todo lo que esté disgregado.

Por último, aunque hay muchos más trabajos que nombrar, pues su producción a lo largo de los años ha sido incesante ${ }^{18}$, no quiero terminar sin hacer referencia a Lo que callan las palabras (Alvar Ezquerra, 2014), precisamente para subrayar su fascinación por las palabras. De boca del autor se desgranan estas certezas:

Las palabras en nuestras manos son verdaderos tesoros, pero su valor intrínseco y su belleza dependen del provecho que sepamos sacar de ellas. Cada una es una piedra en bruto que puede transformarse en una verdadera joya según la maestría del tallador, de su experiencia, y de los conocimientos que tenga. Así hará que su forma final sea una u otra, que pueda ser engarzada de una manera determinada para que su pureza brille cuando la utilicemos (Alvar Ezquerra, 2014: 9).

Se trata de una obra ${ }^{19}$ en la que se recogen numerosas voces con el propósito de informar sobre su origen, el cercano y el más lejano; y con la finalidad de hacernos entender por qué tienen esos sentidos y de hacer transparentes las relaciones entre algunas de ellas, por muy apartadas que estén en cuanto a su significado o su aspecto formal. La lectura de cada uno

17 Estas son las indicaciones que se pueden observar en la Presentación, accesible en este enlace: <https://www.bvfe.es/presentacion-de-la-bvfe.html>. Desde el año 2012 la plataforma ha contado con la financiación de diferentes ayudas ministeriales.

18 No hay que olvidar también que ha participado en la coordinación de libros, como resultado de organizaciones de congresos o responsable de grupo de investigación.

19 Véanse las interesantes reseñas de Fernández de Gobeo (2015) y Luque (2016). 
de sus artículos resulta muy entretenida, pero, además, en todo momento encierran erudición, la que nos pretende transmitir porque «conocer nuestras palabras es conocernos a nosotros mismos» (Alvar Ezquerra, 2014: 12).

Y continúa trabajando, implicado en proyectos de trascendencia, después de toda una vida dedicada al léxico y a sus compilaciones. Siempre con rigor y entusiasmo. Un ejemplo para todos.

\section{BibliogRAFíA}

Alvar Ezquerra, M. (1976): Proyecto de lexicografía española. Barcelona, Planeta.

- (1983): Lexicología y Lexicografía. Guía bibliográfica. Salamanca, Almar.

- (dir.) (1990a): Práctico-Vox. Diccionario ilustrado de la lengua española. Barcelona, Biblograf.

- (dir.) (1990b): Diccionario manual ilustrado de la lengua española. Barcelona, Biblograf.

- (dir.) (1990c): Diccionario actual de la lengua española. Barcelona, Biblograf.

- (1993a): La formación de palabras en español. Madrid, Arco Libros.

- (1993b): Lexicografía descriptiva. Barcelona, Biblograf.

- (dir.) (1994): Diccionario de voces de uso actual. Madrid, Arco Libros.

- (dir.) (1995a): Diccionario ideológico de la lengua española. Barcelona, Biblograf.

- (1995b): The Oxford-Duden Pictorial Spanish-English Dictionary. 2. ${ }^{a}$ ed. Oxford, Clarendon Press (responsable del texto español).

- (dir.) (1995c): Diccionario para la enseñanza de la lengua española. Barcelona, Bibliograf.

- (1996a): «El Tesoro del andaluz». En Ahumada Lara, I. (ed.): Vocabularios dialectales. Revisión crítica y perspectivas. Jaén, Universidad de Jaén, págs. 43-58.

- (1996b): «El diccionario en la enseñanza de la lengua». En Mantecón Ramírez, B. y Zaragoza, F. (eds.): La gramática y su didáctica. Málaga, Miguel Gómez, págs. $75-88$.

- (dir.) (1997a): Diccionario general de la lengua española, Vox. Barcelona, Bibliograf.

- (dir.) (1997b): Diccionario esencial de la lengua española, Vox. Barcelona, Bibliograf.

- (coord.) (1997c): Vocabulario de indigenismos en las crónicas de Indias. Madrid, csic.

- (1998): «Palabras nuevas en los periódicos de hoy». En Álvarez Tejedor, Á. (coord.): La lengua española a finales del milenio. Burgos, Caja de Burgos, págs. 11-44.

- (1999a): «El neologismo: caracterización, formación y aceptabilidad». En González Calvo, J.M. et al. (coords.): Actas v Jornadas de metodología y didáctica de la lengua española. El neologismo. Cáceres, Universidad de Extremadura, págs. 39-66.

- (1999b): «El léxico nuevo en los medios de comunicación». En Carbonero Cano, P. et al. (coords.): Lengua y discurso. Estudios dedicados al profesor Vidal Lamíquiz. Madrid, Arco Libros, págs. 125-144.

- (dir.) (2000): Tesoro léxico de las hablas andaluzas. Madrid, Arco Libros. 
- (2002): De antiguos y nuevos diccionarios del español. Madrid, Arco Libros.

- (2003): Nuevo diccionario de voces de uso actual. Madrid, Arco Libros.

- (2004): «Evocación y sucesos del Tesoro léxico de las hablas andaluzas». En Ahumada Lara, I. (ed.): Lexicografía regional del español. Jaén, Universidad de Jaén, págs. 37-55.

- (2006): «Tendencias de los neologismos en español actual». En Adamo, G. y della Vare, V. (eds.): Che fine fanno $i$ neologismi? A cento anni dalla pubblicazione del Dizionario moderno di Alfredo Panzini. Firenze, Leo S. Olschki Editore, págs. 33-53.

- (2007): «El neologismo español actual». En Luque Toro, L. (ed.): Léxico Español Actual. Actas del I Congreso Internacional de Léxico Español Actual. Venezia, Libreria Editrice Cafoscarina, págs. 11-35.

- (2011): Diccionario de madrileñismos. Voces patrimoniales y populares de la Comunidad de Madrid. Madrid, Ediciones La Librería.

- (2012): «El contenido del Nuevo Tesoro Lexicográfico del Español (s. XIV-1726)». En Cassol, A. et al. (eds.): Metalinguaggi e metatesti. Lingua, letteratura e traduzione. XXIV Congresso AISPI (Padova, 23-26 maggio 2007). Roma, AISPI, págs. 1-16.

- (2013): Las Nomenclaturas del español. Siglos XV-XIX. Madrid, Liceus.

- (2014): Lo que callan las palabras. Madrid, JdeJ Editores.

Alvar Ezquerra, M., Blanco Rodríguez, M.J., López Guzmán, J.M. y Pérez LaGOS, F. (1992): «La gramática interna de los diccionarios vox». En: Euralex’90. Proceedings. Barcelona, Biblograf, págs. 427-435.

Alvar Ezquerra, M., Castillo Carballo, M.A., García Platero, J.M., Jiménez Cuenca, M.Á. y Medina Guerra, A.M. (1999): Manual de redacción y estilo. Madrid, Akal.

Alvar Ezquerra, M. y Medina Guerra, A.M. (1995): Manual de ortografía de la lengua española. Barcelona, Biblograf.

Alvar Ezquerra, M. y Miró Domínguez, A. (1983): Diccionario de siglas y abreviaturas. Madrid, Alhambra.

Alvar Ezquerra, M. y Nieto Jiménez, L. (2006): «La edición del Nuevo Tesoro Lexicográfico del Español (s. XIV-1726)». En Corino, E. et al. (eds.): Atti del XII Congresso Internazionale di Lessicografia. Torino, Edizioni Dell'Orso, vol. I, págs. 365-370.

Castillo Carballo, M.A. (2004): «La fraseología en la modalidad lingüística andaluza. Tratamiento lexicográfico». En Ahumada Lara, I. (ed.): Lexicografía regional del español. Jaén, Universidad de Jaén, págs. 105-122.

- (2013): «Aspectos lexicosemánticos en las combinaciones sintagmáticas habitualizadas en la variedad lingüística andaluza». En Guillén Sutil, R. y Millán Garrido, R. (coords.): Estudios descriptivos y aplicados sobre el andaluz. Sevilla, Universidad de Sevilla, págs. 225-234.

Castillo Carballo, M.A. y García Platero, J.M. (2001): «Algunas peculiaridades léxicas: los datos del DRAE en el Tesoro léxico de las hablas andaluzas». En Castillo Carballo, M.A. y García Platero, J.M. (coords.): Las hablas andaluzas. Problemas y perspectivas. Sevilla, Signatura Ediciones, págs. 121-137. 
Cazorla Vivas, C. y García Aranda, M.Á. (2012): «Manuel Alvar Ezquerra y la Lexicografía». Cálamo FASPE, 59, págs. 7-9.

Cerdá Massó, R. (1989): «Vox. Diccionario General Ilustrado de la Lengua Española». Revista de la Asociación Europea de Profesores de Español, 36-37, págs. 209-214.

Fernández de Gobeo, N. (2015): «Alvar Ezquerra, Manuel (2014). Lo que callan las palabras. Mil voces que enriquecerán tu español». Res Diachronicae, 13, págs. 96-99.

García Aranda, M.Á. (2012): «Manuel Alvar Ezquerra: Diccionario de madrileñismos. Voces patrimoniales y populares de la Comunidad de Madrid». Anuario de Estudios Filológicos, 35, págs. 255-286.

García Aranda, M.Á., Alvar Ezquerra, M., Nuño Álvarez, P., Cazorla Vivas, C. y Arribas Jiménez, M. (2016): El diccionario como herramienta en el aprendizaje/ enseñanza de lenguas. Creación de una plataforma multimedia. Madrid, UCM (en línea: <http://eprints.sim.ucm.es/35383/1/Memoria\%20final.pdf> [consulta: 20 de abril de 2019]).

García Platero, J.M. (2004): «La creación de palabras en Andalucía. A propósito del Tesoro léxico de las hablas andaluzas». En Ahumada Lara, I. (ed.): Lexicografía regional del español. Jaén, Universidad de Jaén, págs. 205-222.

LuQue, R. (2016): «Alvar Ezquerra, Manuel (2014). Lo que callan las palabras. Mil voces que enriquecerán tu español». Rassegna Iberistica, 39.106, págs. 371-373.

Navarro Carrasco, A.I. (1991): «Consideraciones acerca de una Guía Bibliográfica: Lexicología y Lexicografía de M. Alvar Ezquerra». Estudios de Lingüistica Universidad de Alicante (ELUA), 7, págs. 239-242.

- (2001): «Alvar Ezquerra, Manuel (2000). Tesoro léxico de las hablas andaluzas». Estudios de Lingüistica Universidad de Alicante (ELUA), 15, págs. 5-10.

Sánchez Lobato, J. (2012): «Entrevista a Manuel Alvar Ezquerra». Cálamo FASPE, 59, págs. 3-7. 